\title{
Separation of Burnup Monitors in Spent Nuclear Fuel Samples by Liquid Chromatography
}

\author{
Kihsoo Joe," Young-Shin Jeon, Jung-Suck Kim, Sun-Ho Han, Jong-Gu Kim, and Won-Ho Kim \\ Korea Atomic Energy Research Institute, 150 Duckjindong, Yusung, Daejeon 305-353, Korea. "E-mail: ksjoe@kaeri.re.kr \\ Received December 31, 2004
}

\begin{abstract}
A coupled column liquid chromatography system was applied for the separation of the burnup monitors in spent nuclear fuel sample solutions. A reversed phase column was studied for the adsorption behavior of uranyl ions using alpha-hydroxyisobutyric acid as an eluent and used for the separation of plutonium and uranium. A cation exchange column prepared by coating 1-eicosylsulfate onto the reversed phase column was used for the separation of the lanthanides. In addition, retention of $\mathrm{Np}$ was checked with the reversed phase column and cation exchange column, respectively, according to the oxidation states to observe the interference effect for the separation of burnup monitors. This chromatography system showed a great reduction in separation time compared to a conventional anion exchange method. A good agreement from the burnup data was obtained between for this method and a conventional anion exchange method to within $1 \%$ of a difference for the spent nuclear fuel samples of about $40 \mathrm{GWD} / \mathrm{MTU}$.
\end{abstract}

Key Words : Burnup determination, Liquid chromatography, Actinides separations, Lanthanides separations, Reversed phase chromatography

\section{Introduction}

Burnup determination is one of the important works related to the studies for the spent nuclear fuel characterization. ${ }^{1}$ For this work, the determination of fission product, and heavy elements such as plutonium and uranium is required in the nuclear fuel samples. Of the fission products, neodymium $\left({ }^{148} \mathrm{Nd}\right)$ is well known to be used as a burnup monitor and the amount of ${ }^{148} \mathrm{Nd}$ as well as plutonium and uranium are used for the burnup calculation after the determinations by a mass spectrometry. ${ }^{2}$ Generally, anion exchange chromatography has been used for the separation of lanthanides, plutonium and uranium in spent nuclear fuel solutions. ${ }^{2}$ However, this method is timeconsuming and a laborous operation. Therefore, high performance liquid chromatography has been applied to the separation of the lanthanum in uranium-thorium oxide fuel for the burnup measurement and metal impurities for the quality control of a fuel fabrication ${ }^{3-5}$ and transition metals in water and food. ${ }^{6}$ Charles A. Lucy et al. developed a coupled column system which is a reversed phase column coupled to a cation exchange column and was used for the determination of a trace amount of lanthanides and transition metals in uranium matrix sample solutions using alpha-hydroxyisobutyric acid (HiBA) as an eluent. ${ }^{5}$ That is, the lanthanides and transition metals were individually separated on the cation exchange column after the uranium matrix was removed by adsorption onto the reversed phase column.

For the burnup determination of spent nuclear fuels by liquid chromatography, a large sample size of uranyl solutions would be injected onto the column because the neodymium content which is a burnup monitor is very low in the spent fuel compared to the uranium content.
Consequently, the capacity of the column should be measured to estimate an appropriate sample amount to be injected. In high concentration liquid chromatography, the retention time and the bandwidth are dependent on the amount of the sample size. ${ }^{7}$

Accordingly, in this study the elution behavior for a large sample size of uranyl ions on the reversed phase column was studied using the HiBA eluent with regards to the column capacity, peak shape, retention time etc. In addition, the retention of $\mathrm{Np}$ was also checked with a reversed phase column and a cation exchange column, respectively, to observe the interference effect on the separation of the elements associated with the burnup determinations such as neodymium, plutonium and uranium. The separation of lanthanides was performed on the cation exchange column to obtain the optimum separation condition by applying isocratic or stepwise gradient elution of the HiBA eluent. Finally, a coupled column liquid chromatography system was applied to the separation of $\mathrm{Nd}, \mathrm{Pu}$ and $\mathrm{U}$ from the spent nuclear fuel sample solutions by a stepwise gradient elution of the HiBA eluent for the burnup determination.

\section{Experimental Section}

Reagent and apparatus. The ion chromatography system of the Metrohm company consisted of a 709 IC pump, 733 IC separation center, 812 IC injection valve, 816 IC eluent selector, 752 peristaltic pump unit, 762 IC interface and a Lambda 1010 UV/Vis detector (Bishoff Co). This system was controlled by IC Net 2.1 Metrodata software installed in a personal computer. A LC- 18 column $(15 \mathrm{~cm} \times 0.46 \mathrm{~cm}, 5$ $\mu \mathrm{m}$ particle size, Supelco Co.) was used as the reversed phase column and a base material for the cation exchange 
column. A solenoid switching valve (Cole-Parmer Instrument P/N\# 98300-02, 12V DC) was used for the fraction collection of the elements separated and a thermoionization mass spectrometer, Finnigan Mat 262 of the Finnigan Mat $\mathrm{Co}$, was used for the measurement of the isotope ratios of the elements.

Alpha-hydroxyisobutyric acid from the Aldrich Chemical Co $(99 \%)$ and 1-eicosylsulfate $\left(\mathrm{C}_{20} \mathrm{H}_{41} \mathrm{SO}_{4}{ }^{-}\right)$from the Sigma Chemical Co were used as an eluent and a cation exchanger, respectively. 2.2-[1.8-dihydroxy-3.6-disulfo-2.7-naphthalenebis-(azo)] dibenzene arsonic acid (Arsenazo III) from the Sigma Chemical Co was used as a coloring reagent for the detection of the elements. Plutonium, uranium and lanthanides were detected by an absorption of $658 \mathrm{~nm}$ after a post-column reaction with Arsenazo III. Acetonitrile from the Kanto Co and methanol from the Oriental Chem. Ind. were used as a coating solvent for the cation exchanger and an organic modifier of the eluent, respectively. Deionized water for all the experiments was used after treatment with a Milli-Q Water System (Millipore Co). Working solutions of the uranium and lanthanides were prepared by a dilution of a standard solution (10000 $\mu \mathrm{g} / \mathrm{mL}$ or $1000 \mu \mathrm{g} / \mathrm{mL}$, Spex Co) to an appropriate concentration. The standard solutions of the plutonium and neptunium were prepared by a dissolution of $\mathrm{PuO}_{2}$ (NBL, CRM No 122) and a dilution of ${ }^{237} \mathrm{~Np}$ stock solution (DAMRI, CEA, France), respectively.

Experimental procedure. Uranyl solutions were injected onto the reversed phase columns as a variation of the uranium amount from 0.01 to $0.6 \mathrm{mg}$ using different concentrations of the HiBA eluents. Column capacities were obtained from the loading factors which were measured from the retention times of the peaks. In addition, the retention behavior of the neptunium species was studied according to the oxidation states on the reversed phase column and the cation exchange column, respectively, using the HiBA eluent. A chromatographic system with a coupled column was used after modification from that reported in other's work ${ }^{5}$ and applied to the separation of the plutonium, uranium and lanthanides.

The uranyl sample solution was made to be $0.1 \mathrm{M}$ HiBA of $\mathrm{pH} 3.0$ in order to quantitatively make the uranyl-HiBA complex prior to injection. Uranium sample solutions containing plutonium and lanthanides were injected and the elements were separated by a stepwise gradient of the HiBA eluent as shown in Table 1. Finally, the spent nuclear fuel sample solutions were injected after an optimum separation condition was obtained. The fraction of each element was collected using a solenoid switching valve and determined by an isotope dilution mass spectrometry for the burnup data.

\section{Results and Discussion}

Adsorption behavior of the uranyl ions on the reversed phase column. A study of the adsorption behavior of a large amount of uranium on the reversed phase column is required for the separation of the actinides and lanthanides. Column capacities were measured to estimate a maximum sample amount for an injection from the retention times of the peaks. $^{7,8}$ In Figure 1 and Figure 2 the overlays of the chromatograms are shown with an increasing of the uranium amount injected from 0.01 to $0.6 \mathrm{mg}$ using $0.25 \mathrm{M}$ and 0.025 M HiBA as the eluents, respectively. As shown in Figure 1 and Figure 2 the retention times of the peaks decreased with an increasing of the sample amount, and the peak shapes with a rectangular triangle type (Fig. 1) is known to be a convex isotherm such as a Langmuir isotherm and the concave peak shape with tailing in Figure 2 is explained due to the decreasing influence of the column efficiency with an increasing of the loading factor at a low concentration of the eluent. ${ }^{7-9}$ In these eluent conditions, column capacities were measured from the loading factors using equations (1) and (2) ${ }^{7,8}$ Where, $L_{f}$ is the loading factor, $t_{f}$ is the retention time of the peak, $t_{p}$ is the injection time of the sample solution, $t_{r, o}$

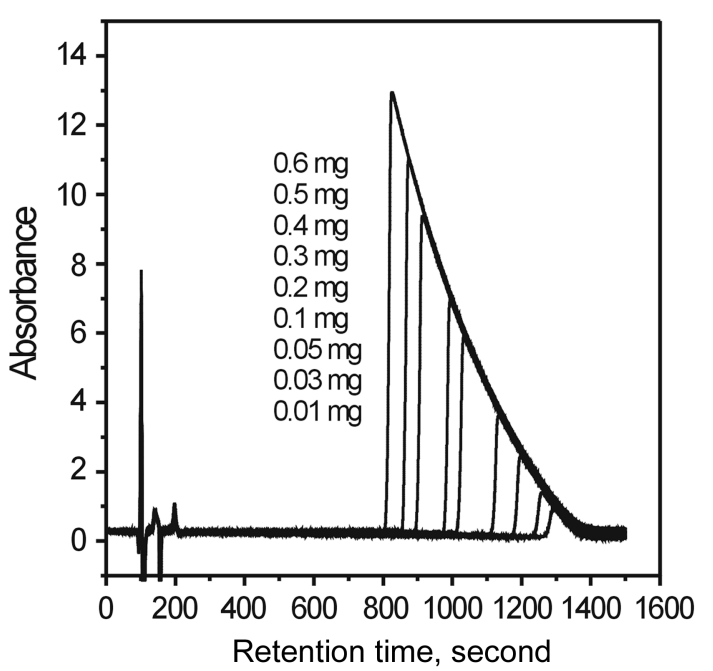

Figure 1. An overlay of the chromatograms of uranium on the reversed phase column. column; LC-18 $(15 \mathrm{~cm} \times 0.46 \mathrm{~cm}, 5 \mu \mathrm{m}$ particle size), eluent; $0.25 \mathrm{M} \mathrm{HiBA}, \mathrm{pH} 3.8$, flow rate; $1 \mathrm{~mL} / \mathrm{min}$., sample injected; $100 \mu \mathrm{L}$ of $\mathrm{U}$ in $0.1 \mathrm{M}$ HiBA matrix at $\mathrm{pH} \sim 3$, detection; $414 \mathrm{~nm}$.

Table 1. Stepwise gradient elution for the separation of $\mathrm{Pu}, \mathrm{U}$ and lanthanides from the spent nuclear fuel sample solutions

\begin{tabular}{cccc}
\hline Time $(\mathrm{min})$ & Eluent & RPC & CEC \\
\hline $0-6$ & $0.025 \mathrm{M} \mathrm{HiBA}, \mathrm{pH} 3.8$ & adsorption of Pu and & adsorption of lanthanides \\
$6-25$ & $0.1 \mathrm{M} \mathrm{HiBA}, \mathrm{pH} 3.8$ & - & separation of lanthanides \\
$25-37$ & $0.1 \mathrm{M} \mathrm{HiBA}-25 \% \mathrm{CH}_{3} \mathrm{OH}, \mathrm{pH} 3.8$ & elution of Pu and $\mathrm{C}$ & - \\
$37-42$ & $0.1 \mathrm{M} \mathrm{HiBA}-25 \% \mathrm{CH}_{3} \mathrm{OH}, \mathrm{pH} 3.8$ & column washing & - \\
\hline
\end{tabular}

*RPC: reversed phase column (LC-18, $15 \mathrm{~cm} \times 0.46 \mathrm{~cm}, 5 \mu \mathrm{m}$ particle size), CEC: cation exchange column (1-eicosylsulfate coated onto LC-18) 


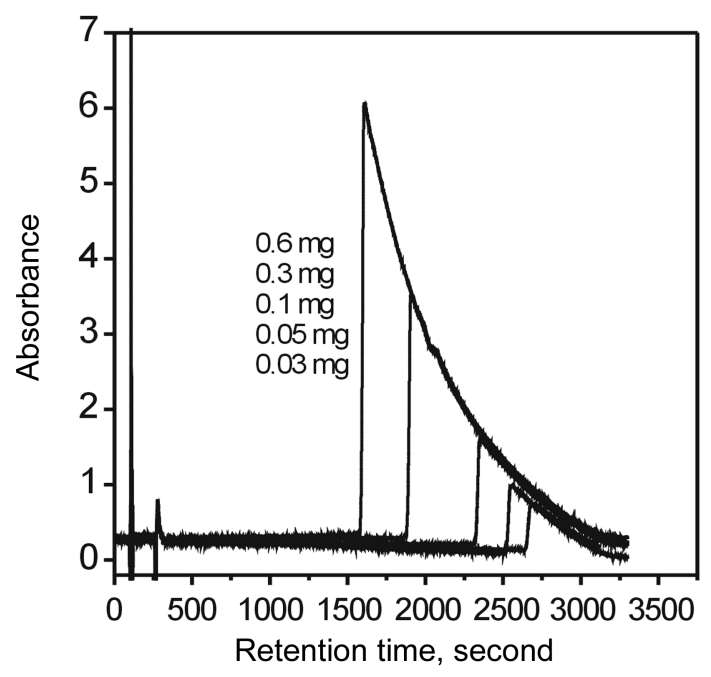

Figure 2. An overlay of the chromatograms of the uranium on the reversed phase column. eluent; $0.025 \mathrm{M}$ HiBA, $\mathrm{pH} 3.8$, other condition; same as in Figure 1.

$$
\begin{gathered}
L_{f}=\left[1-\left[\left(t_{f}-t_{o}-t_{p}\right) /\left(t_{r, o}-t_{o}\right)\right]^{1 / 2}\right]^{2} \\
\text { Capacity }=C_{m o} V / L_{f}
\end{gathered}
$$

and $t_{o}$ are the retention times of the analytical sample size and at a solvent peak, respectively, $C_{m o}$ is the concentration of the sample injected, and $V$ is the volume of the sample injected. The reversed phase column with a $5 \mu \mathrm{m}$ particle size used in this work showed similar capacities such as $\sim 13$ mg $U$ and $\sim 14 \mathrm{mg} U$ according to the eluent concentration of $0.25 \mathrm{M} \mathrm{HiBA}$ and $0.025 \mathrm{M}$ HiBA, respectively. It took about 50 min until the uranyl ion was eluted completely at $0.025 \mathrm{M}$ HiBA eluent as shown in Figure 2. However, in the case of adding a strong organic solvent such as methanol to

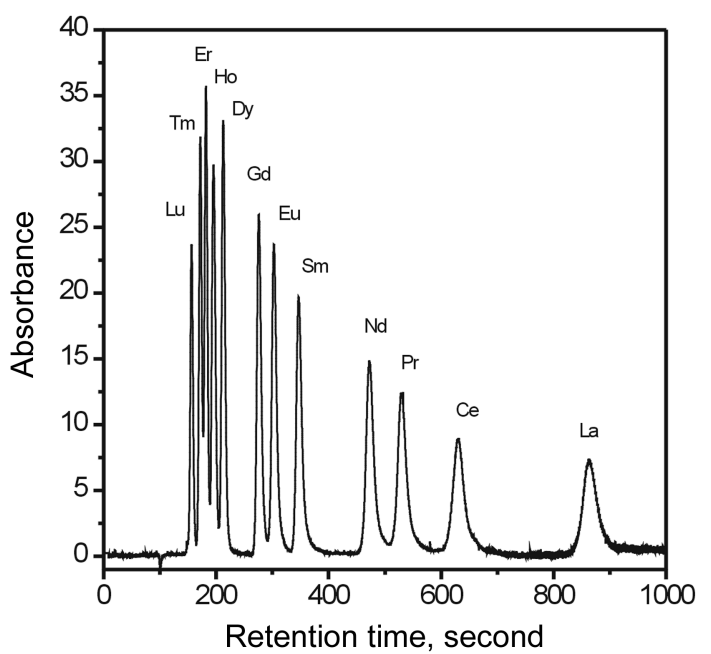

Figure 3. Chromatogram of lanthanides separated on the cation exchange column. column; 1-eicosylsulfate coated onto LC-18, eluent; $0.1 \mathrm{M}$ HiBA, pH 3.8, sample injection; $20 \mu \mathrm{L}$ of $2 \mu \mathrm{g} / \mathrm{mL}$ each lanthanide, flow rate; $1 \mathrm{~mL} / \mathrm{min}$, detection: $658 \mathrm{~nm}$ after postcolumn reaction with Arsenazo III. the eluent, the elution time was greatly decreased and the peak shape was sharpened as well. In this study, the plutonium and uranium adsorbed onto the reversed phase column were quantitatively removed within $7 \mathrm{~min}$ at a flow rate of $1 \mathrm{~mL} / \mathrm{min}$ using the eluent of $0.1 \mathrm{M} \mathrm{HiBA}$ containing $25 \% \mathrm{CH}_{3} \mathrm{OH}$ (Table 1 and Fig. 7). Accordingly, at the condition of $0.025 \mathrm{M} \mathrm{HiBA}$ eluent, the sample amount to be injected can be increased up to $3 \mathrm{~mL}$ of $5 \mathrm{mg} \mathrm{U} / \mathrm{mL}$ solution and the measured capacities were slightly lower than that reported in other work. ${ }^{5}$

Separation of the lanthanides on the cation exchange column. An individual separation of the lanthanides using HiBA eluent on the cation exchanger has been reported to be most effective. ${ }^{10}$ Especially, a high capacity column has a shortcoming in that it causes a bad resolution due to peak broadening and a long retention time. Accordingly, an equilibrated ion exchanger which is an ion pairing reagent having a relatively shorter alkyl chain $\left(\mathrm{C}_{6} \sim \mathrm{C}_{8}\right)$ has been added to the eluent or a permenantly sorbed ion exchanger which is an ion pairing reagent having a longer alkyl chain $\left(\mathrm{C}_{20} \sim \mathrm{C}_{40}\right)$ has been coated onto reversed phase column to increase the resolution and decrease the retention time. ${ }^{11}$ The advantage of this kind of ion exchanger is to control easily the column capacity by varying the concentration of the ion pairing reagents to be added. ${ }^{10,11}$ and another advantage is given to the radioactive samples because the functional group of the ion exchanger damaged by radiolysis can be easily refilled.

In this work, the cation exchanger was prepared by coating 1-eicosylsulfate onto the LC-18 column. ${ }^{11}$ The prepared column capacity was $\sim 0.1$ meq which is much lower than that of a commercial ion exchanger. For a low capacity column where an ion exchanger is coated at the surface of the octadecyl phase, it gives a high resolution between the peaks due to a faster mass transfer at the surface of the ion exchanger. ${ }^{11}$ In Figure 3, $40 \mathrm{pg}$ each of 12

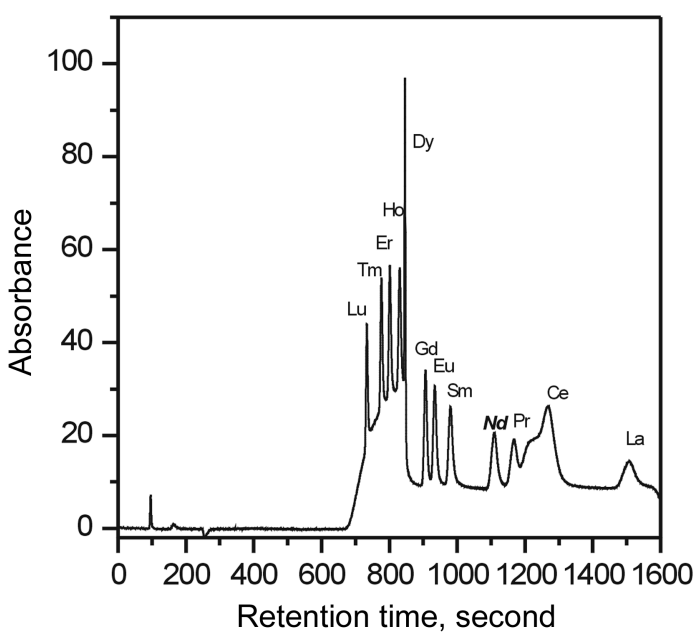

Figure 4. Chromatogram of lanthanides separated by a stepwise gradient elution of HiBA eluent. sample injected; $20 \mu \mathrm{L}$ of $2 \mu \mathrm{g} /$ $\mathrm{mL}$ each lanthanide, flow rate; $1 \mathrm{~mL} / \mathrm{min}$, gradient condition; same as in Table 1 . 
lanthanides were individually resolved to the baseline by an isocratic elution of $0.1 \mathrm{M} \mathrm{HiBA}(\mathrm{pH} 3.8)$ as an eluent. Figure 4 shows the chromatogram of the lanthanides obtained by a stepwise gradient of the eluent concentration at the condition as shown in Table 1. As shown in Figure 4 the total lanthanides were also individually separated. However, the baseline is not constant due to the difference of the absorbance in the detector caused by a variation of the eluent concentrations during the chromatography.

Elution behavior of $\mathrm{Np}$ species. Elution of $\mathrm{Np}$ was performed on the reversed phase column and cation exchange column, respectively, to observe the interference effect for the separation of the neodymium, plutonium and uranium from the spent nuclear fuel sample solutions. The neptunium exists as $\mathrm{Np}^{3+}, \mathrm{Np}^{4+}, \mathrm{NpO}_{2}{ }^{+}, \mathrm{NpO}_{2}{ }^{2+}$ and $\mathrm{NpO}_{5}{ }^{3-}$ in an aqueous solution and the $\mathrm{NpO}_{2}{ }^{+}$mainly exists in a dilute acid solution. ${ }^{12}$ The neptunium species were chromatographed at some oxidation states. Figure 5 shows the chromatograms obtained from the injection of the $\mathrm{Np}$ sample solutions on the reversed phase column at different eluent concentrations and sample matrix. In Figure 5a, a single peak, $\mathrm{NpO}_{2}{ }^{+}$, was observed at a solvent peak position (2.15 min) while two peaks were observed at dilute eluent concentration as shown in Figure 5b. The small peak with longer retention time in Figure $5 \mathrm{~b}$ seems to be $\mathrm{NpO}_{2}{ }^{2+}$. This $\mathrm{NpO}_{2}{ }^{2+}$ peak was confirmed by comparison with Figure $5 \mathrm{c}$ which was obtained from the injection of the Np solution
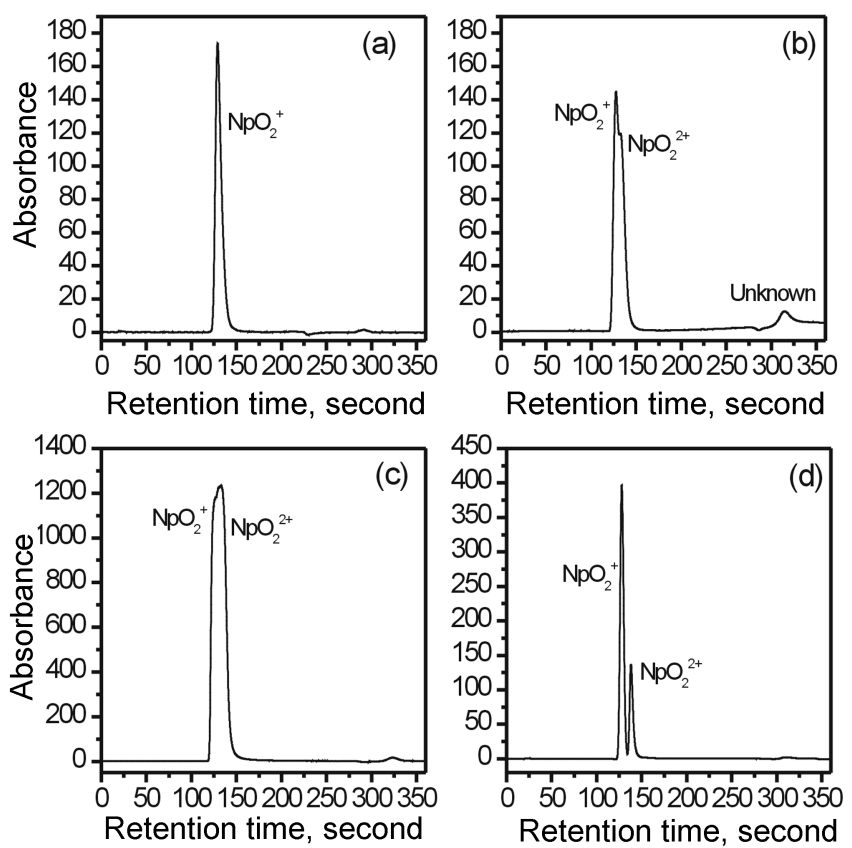

Figure 5. Chromatogram of $\mathrm{Np}$ species obtained on the reversed phase column. column; LC-18 $(15 \times 0.46 \mathrm{~cm}, 5 \mu \mathrm{m}$ particle size $)$, sample injection: $100 \mu \mathrm{L}$, Flow rate: $1 \mathrm{~mL} / \mathrm{min}$., Detection: $658 \mathrm{~nm}$ after post-column reaction with Arsenazo III (a) eluent; $0.1 \mathrm{M}$ HiBA pH 3.8, sample; $4.3 \mu \mathrm{g} \mathrm{Np/mL}$ in $0.1 \mathrm{M} \mathrm{HiBA}$ (b) eluent; $0.025 \mathrm{M}$ HiBA pH 3.8, sample; $4.3 \mu \mathrm{g} \mathrm{Np} / \mathrm{mL}$ in $0.1 \mathrm{M} \mathrm{HiBA}$ (c) eluent; $0.025 \mathrm{M}$ HiBA pH 3.8, sample; $66.6 \mu \mathrm{g} \mathrm{Np} / \mathrm{mL}$ oxidized by $\mathrm{KBrO}_{3}$ in $0.1 \mathrm{M} \mathrm{HiBA}$, (d) eluent; $0.025 \mathrm{M} \mathrm{HiBA} \mathrm{pH} \mathrm{3.8,} \mathrm{sample;}$ $3.4 \mu \mathrm{g} \mathrm{Np} / \mathrm{mL}$ in $0.01 \mathrm{M} \mathrm{HNO}_{3}$ after oxidation with $\mathrm{KBrO}_{3}$ at the same conditions as in Figure 5b. In Figure $5 \mathrm{c}$ the $\mathrm{NpO}_{2}{ }^{2+}$ peak is higher even though it is not resolved from the $\mathrm{NpO}_{2}{ }^{+}$peak. However, the $\mathrm{NpO}_{2}{ }^{2+}$ peak was resolved to the baseline at the sample matrix of dilute nitric acid as shown in Figure $5 \mathrm{~d}$. The longer retention time of $\mathrm{NpO}_{2}{ }^{2+}$ than $\mathrm{NpO}_{2}{ }^{+}$seems to be due to the stronger adsorption of the $\mathrm{NpO}_{2}{ }^{2+}-\mathrm{HiBA}$ complex onto the reversed phase column than the $\mathrm{NpO}_{2}{ }^{+}-\mathrm{HiBA}$ complex because of the higher stability constant of $\mathrm{NpO}_{2}{ }^{2+}$ with HiBA. ${ }^{13,14}$

Figure 6(a-c) show the chromatograms of $\mathrm{NpO}_{2}^{+}$and $\mathrm{NpO}_{2}{ }^{2+}$ obtained on the cation exchange column. In Figure 6a a single peak of the $\mathrm{NpO}_{2}{ }^{+}$with retention of about 2 min was observed at the condition of $0.1 \mathrm{M}$ HiBA eluent. However, as shown in Figure $6 \mathrm{~b}$ at a lower concentration of the eluent, $0.025 \mathrm{M} \mathrm{HiBA}$, two peaks, $\mathrm{NpO}_{2}{ }^{+}$and $\mathrm{NpO}_{2}{ }^{2+}$, were observed at the same condition as in Figure $6 \mathrm{a}$. The peak with longer retention time seems to be $\mathrm{NpO}_{2}{ }^{2+}$. The retention time and peak shape at a lower concentration of the eluent (Fig. 6b) were longer and broader than those at the higher concentration of the eluent (Fig. 6a). In Figure $6 \mathrm{c}$ the $\mathrm{NpO}_{2}{ }^{2+}$ peak which was obtained after oxidation by bromate prior to injection was increased compared to that in Figure $6 b$.

The results obtained above said that the retention time and the peak shape of the $\mathrm{Np}$ species on the cation exchange column were longer and broader than those on the reversed phase column. The reason for the peak broadening on cation
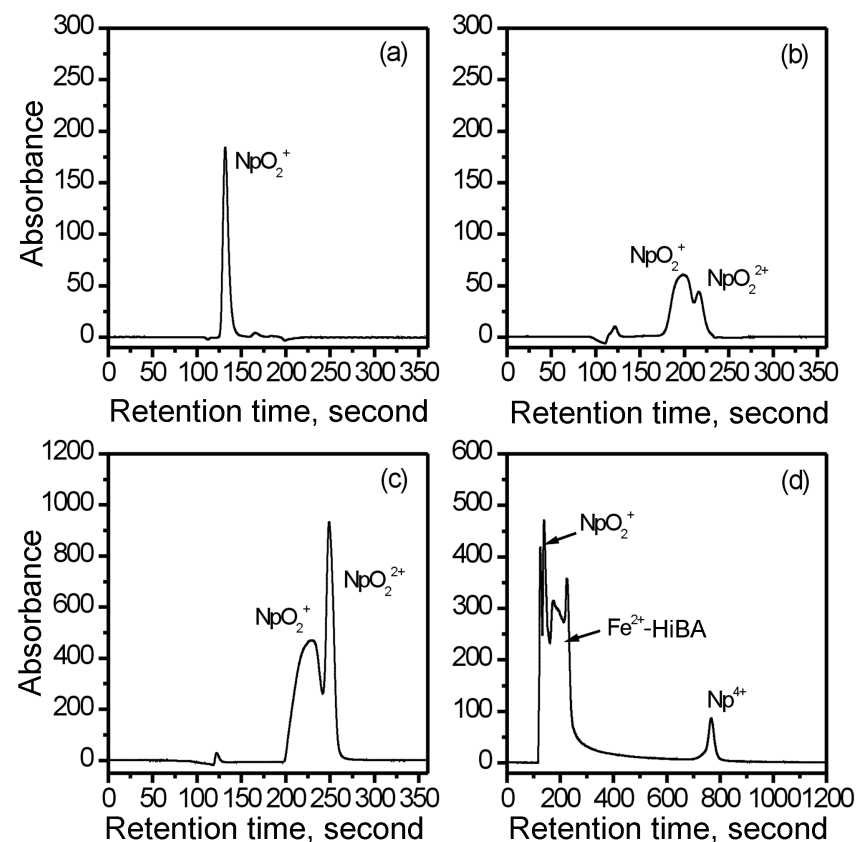

Figure 6. Chromatogram of $\mathrm{Np}$ species obtained on the cation exchange column (a-c) and reversed phase column (d). (a) eluent; $0.1 \mathrm{M}$ HiBA, pH 3.8, sample; $4.3 \mu \mathrm{g} \mathrm{Np} / \mathrm{mL}$ in $0.1 \mathrm{M}$ HiBA, (b) eluent; $0.025 \mathrm{M}$ HiBA, pH 3.8, sample; $4.3 \mu \mathrm{g} \mathrm{Np} / \mathrm{mL}$ in $0.1 \mathrm{M}$ HiBA, (c) eluent; $0.025 \mathrm{M}$ HiBA, pH 3.8, sample; $33.3 \mu \mathrm{g} \mathrm{Np} / \mathrm{mL}$ oxidized by $\mathrm{KBrO}_{3}$ in $0.1 \mathrm{M} \mathrm{HNO}_{3}$, (d) eluent; $0.16 \mathrm{M} \mathrm{HiBA}-4 \%$ $\mathrm{CH}_{3} \mathrm{OH}, \mathrm{pH} 3.8$, sample; $26.6 \mu \mathrm{g} \mathrm{Np} / \mathrm{mL}$ reduced with $\mathrm{Fe}^{2+}$ in 0.1 $\mathrm{M} \mathrm{H}_{2} \mathrm{SO}_{4}$ other conditions; same as in Fig. 5. 
exchange column at a low concentration of the eluent seems due to the mixed effect of the ion interaction between the metal ion and the counter ion of the cation exchanger, and the hydrophobic interaction between the metal-HiBA complex and the long alkyl chain of the cation exchanger. But the exact reason was not identified in this study. In Figure $6 \mathrm{~d}$ the $\mathrm{Np}^{4+}$ peak was obtained on the reversed phase column after reduction of $\mathrm{NpO}_{2}{ }^{+}$with the ferrous iron. It showed a long retention time $(\sim 13 \mathrm{~min})$ at the eluent of 0.16 M HiBA containing $4 \% \mathrm{CH}_{3} \mathrm{OH}$. The long retention time of $\mathrm{Np}^{4+}$ seems to be due to strong adsorption of $\mathrm{Np}^{4+}$-HiBA complex onto the reversed phase column. The retention time of $\mathrm{Np}^{4+}$ was shortened $(\sim 3 \mathrm{~min})$ at the $0.1 \mathrm{M} \mathrm{HiBA}$ eluent containing $25 \% \mathrm{CH}_{3} \mathrm{OH}$ and greatly increased ( $>25 \mathrm{~min}$ ) at the lower concentration of HiBA $(0.025 \mathrm{M})$, respectively. The retention times of the $\mathrm{Np}^{4+}$ and $\mathrm{NpO}_{2}{ }^{+}$observed in Figure $6 \mathrm{~d}$ were in a good agreement with those reported in other work. $^{15}$

Separation of the burnup monitors on the coupled column. A stepwise gradient elution of the HiBA eluent concentration was attempted to separate the lanthanides, plutonium and uranium from a synthetic sample solution using a coupled column system as shown in Table 1. As a first step $0.025 \mathrm{M} \mathrm{HiBA}(\mathrm{pH}$ 3.8) eluent flowed through both the reversed phase column and the cation exchange column in series for $6 \mathrm{~min}$ after an injection of the sample solution. At this step uranium and plutonium are adsorbed onto the reversed phase column and the lanthanides are retained on the cation exchange column after passing through the reversed phase column because the formed uranyl-HiBA complexes stay onto the reversed phase column during this time as shown in Figure 2 and the lanthanides don't make neutral complexes with $\mathrm{HiBA}$ at a low concentration of HiBA due to their lower stability constants. ${ }^{13}$ As a second step 0.1 M HiBA only flowed through the cation exchange column for $19 \mathrm{~min}$ to separate the lanthanides individually as shown in Figure 4. As for the third step $0.1 \mathrm{M}$ HiBA containing $25 \% \mathrm{CH}_{3} \mathrm{OH}$ only flowed through the reversed phase column for 12 min to elute the plutonium ( 29 min) and uranium ( $31 \mathrm{~min})$ adsorbed, and for $5 \mathrm{~min}$ additionally for the column washing. Finally, the eluent condition returned to the original state and was maintained for $20 \mathrm{~min}$ to make the system equilibrated. At this eluent condition, plutonium ions elute earlier than uranyl ions because the stability constant between $\mathrm{PuO}_{2}{ }^{2+}$ and $\mathrm{HiBA}$ is higher than that between $\mathrm{UO}_{2}{ }^{2+}$ and $\mathrm{HiBA} .{ }^{13}$

The elution of $\mathrm{Np}$ was also performed individually using the coupled column liquid chromatography. Neptunium was eluted at a short retention time $(\sim 5 \mathrm{~min})$ through both the reversed phase column and the cation exchange column using $0.025 \mathrm{M}$ HiBA eluent at a flow rate of $1 \mathrm{~mL} / \mathrm{min}$. The retention time of $\mathrm{Np}$ is expressed as sum of the retention times on both the two columns, which was previously discussed in Figure 5 and 6.

In Figure 7, a good separation of $\mathrm{Np}, \mathrm{Nd}, \mathrm{Pu}$ and $\mathrm{U}$ was obtained with the retention times of $5.5 \mathrm{~min}, 14.7 \mathrm{~min}, 29.6$ min and $31.1 \mathrm{~min}$, respectively, from a synthetic sample solution which was prepared to be $0.12 \mu \mathrm{g} / \mathrm{mL}$ of $\mathrm{Np}, 0.1-$ $0.6 \mu \mathrm{g} / \mathrm{mL}$ of lanthanides, $2.5 \mu \mathrm{g} / \mathrm{mL}$ of $\mathrm{Pu}$ and $250 \mu \mathrm{g} / \mathrm{mL}$ of U. The heavier lanthanides were not resolved individually because only an isocratic elution of $0.1 \mathrm{M} \mathrm{HiBA}$ was applied in this system. However, this isocratic elution has no problem for the separation of $\mathrm{Nd}$ followed by the determination of ${ }^{148} \mathrm{Nd}$ by mass spectrometry for a burnup determination. In the case of the samples containing Am and $\mathrm{Cm}$, these elements were reported to elute at the retention time ahead of $\mathrm{UO}_{2}{ }^{2+}$ on the reversed phase column ${ }^{15}$ and at the position of $\mathrm{Eu}$ and $\mathrm{Gd}$ ahead of $\mathrm{Nd}$ on the cation exchnage column, ${ }^{16}$ respectively, using the HiBA eluent. Accordingly, based on the results studied until now, the actinides such as $\mathrm{Np}$, Am and $\mathrm{Cm}$ have been proved not to

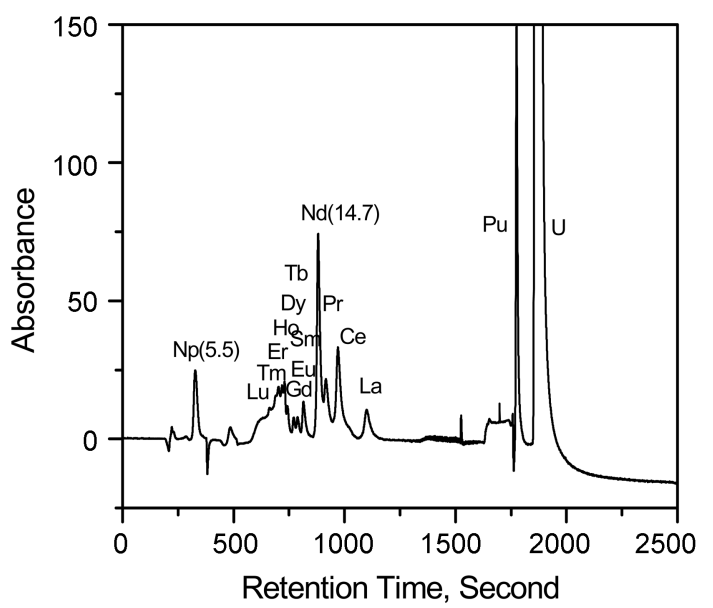

Figure 7. Separation of $\mathrm{Np}, \mathrm{Pu}, \mathrm{U}$ and lanthanides in synthetic sample solution by stepwise gradient elution. sample: U 250, Pu 2.5, Np 0.12, La 0.3, Ce 0.6, Pr 0.3, Nd 1, Sm 0.2, Eu 0.1, Gd 0.1, Tb 0.1, Dy 0.1, Ho 0.1, Er 0.1, Tm 0.1 and Lu $0.1 \mu \mathrm{g} / \mathrm{mL}$, gradient condition; same as in Table 1, sample injection; $100 \mu \mathrm{L}$, flow rate; $1 \mathrm{~mL} / \mathrm{min}$., detection; $658 \mathrm{~nm}$ after post-column reaction with Arsenazo III

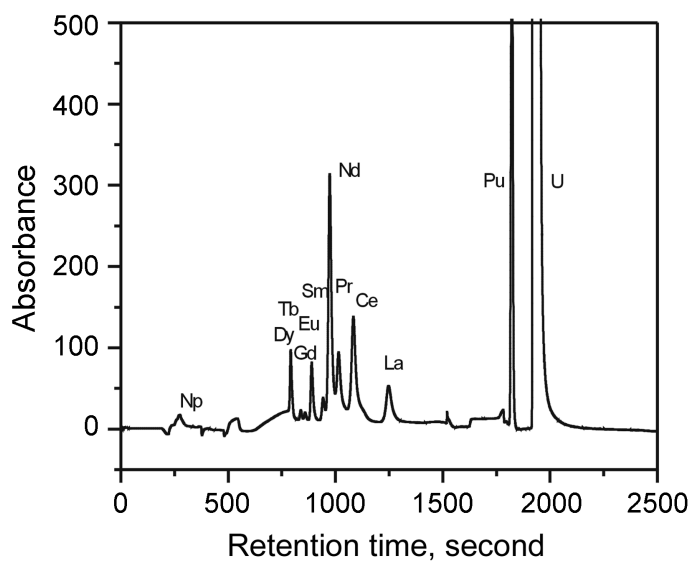

Figure 8. Separation of $\mathrm{Nd}, \mathrm{Pu}$ and and $\mathrm{U}$ in the spent nuclear fuel sample solutions for burnup determination using coupled column liquid chromatography. sample name; J14E11(No4), elution condition; same as in Table 1 , sample injection; $1000 \mu \mathrm{L}$ of $0.1 \mathrm{M}$ HiBA matrix, $\mathrm{pH} 3.0$, Flow rate; $1 \mathrm{~mL} / \mathrm{min}$, detection; $658 \mathrm{~nm}$ after post-column reaction with Arsenazo III 
Table 2. Burnup data for the spent nuclear fuel samples determined by coupled column liquid chromatography

Unit: MWD/MTU

\begin{tabular}{cccc}
\hline $\begin{array}{c}\text { Method } \\
\text { Sample }\end{array}$ & $\begin{array}{c}\text { Coupled } \\
\text { Column System } \\
\text { (A) }\end{array}$ & $\begin{array}{c}\text { Anion Exchange } \\
\text { Chromatography } \\
\text { (B) }\end{array}$ & $\begin{array}{c}\text { Difference } \\
\text { 100(A-B)/B }\end{array}$ \\
\hline J14E11(No 4) & $35897.3 \pm 707$ & 36200 & $-0.8 \%$ \\
J14E11(No 7) & 36334.7 & 36200 & $+0.4 \%$ \\
J14E11(No 9) & 39037.1 & 39000 & $+0.1 \%$ \\
\hline
\end{tabular}

interefere for the separation of $\mathrm{Nd}, \mathrm{Pu}$ and $\mathrm{U}$ from the spent fuel sample solutions by a coupled column liquid chromatography. A full procedure for the separations was finished within about $40 \mathrm{~min}$ of the running time. Especially, in this study the stepwise gradient elution was selected rather than a linear gradient elution because this elution technique gives a better reproducibility for the retention time of a burnup monitors even though the linear gradient elution shows a better resolution for an individual separation of the total lanthanides.

In Figure 8 the spent nuclear fuel sample solution was applied for the separation of $\mathrm{Nd}, \mathrm{Pu}$ and $\mathrm{U}$. The contents of ${ }^{148} \mathrm{Nd}, \mathrm{Pu}$ and $\mathrm{U}$ were determined by an isotope dilution mass spectrometry after separation and collection.

Especially, more attention was paid in this work to get rid of the memory effect caused by a high concentration of uranium matrix by flowing an excess amount of the eluent prior to another sample injection. Any chromatographic problem associated with an injection volume was not observed up to $1 \mathrm{~mL}$ of the sample solution in which uranium concentration was about $150 \mu \mathrm{g} / \mathrm{mL}$. The amount of $\mathrm{Nd}\left({ }^{148} \mathrm{Nd}\right), \mathrm{Pu}$ and $\mathrm{U}$ separated were determined by mass spectrometry and the burnup was calculated using equation $(3)^{2}$. Where, $B U$ is the burnup (atom $\%$ fission), $N$ is the atom number of the burnup monitor $\left({ }^{148} \mathrm{Nd}\right), Y$ is the fission yield of the burnup monitor $\left({ }^{148} \mathrm{Nd}\right)$ and $H E$ is the atom number of the heavy elements ( $\mathrm{Pu}$ and $\mathrm{U}$ ). In Table 2 the burnup data determined by this method is shown and the results showed a good agreement to within $1 \%$ of a difference between this method and the conventional anion exchange method.

$$
B U=\frac{(N / Y) 100}{(H E+N / Y)}
$$

\section{Conclusion}

A coupled column liquid chromatography system was successfully applied for the separation of burnup monitors such as lanthanides and actinide elements in spent nuclear fuel sample solutions with a short separation time by a single injection of the sample solution. This separation method also showed a good reliability and much convenience when compared to a conventional anion exchange method for burnup determinations.

In the future, this method will contribute to the service activities for burnup determinations of spent nuclear fuel samples and also contribute to a spent fuel's characterization.

Acknowledgements. This study was performed as a part of the Long- and Mid-term Nuclear R\&D Programs funded from the Ministry of Science and Technology of Korea.

\section{References}

1. Maeck, W. J.; Larson, R. P.; Rein, J. E. TID-26209 1973, 1-75.

2. ASTM American Society for Testing and Materials; 1996; E32196, p 1-9.

3. Knight, C. H.; Cassidy, R. M.; Recoskie, B. M.; Green, L. W. Anal. Chem. 1984, 56(3), 474-478.

4. Cassidy, R. M.; Elchuck, S.; Green, L. W.; Knight, C. H.; Miller, F. C.; Recoskie, B. M. J. Radioanal. and Nucl. Chem. 1990, 139(1), 55-64.

5. Lucy, C. A.; Gureli, L.; Elchuck, S. Anal. Chem. 1993, 65(22), 3320-3325.

6. Quifen, H.; Guangyu, Y.; Haitao, L.; Xi, T.; Jiayuan, Y. Bull. Korean Chem. Soc. 2004, 25(5), 694-698.

7. Golshan-shirazi, S.; Guiochon, G. Anal. Chem. 1988, 60, 23642374.

8. Golshan-shirazi, S.; Guiochon, G. Anal. Chem. 1989, 61, 462-467.

9. Guiochon, G.; Ghodbane, S.; Gloshan-Shirazi, S.; Huang, J.-X.; Katti, A.; Lin, B.-C.; Ma, Z. Talanta 1989, 36(1/2), 19-33.

10. Elchuk, S.; Lucy, C. A.; Burns, K. I. Anal. Chem. 1992, 64(20), 2339-2343.

11. Cassidy, R. M.; Elchuk, S. Anal. Chem. 1982, 54(9), 1558-1563.

12. Burney, G. A.; Harbour, R. M. NAS-NS-3060 1974, 21-25.

13. Martell, A. E.; Smith, R. M. Critical Stability Constants: Other Organic Ligands; Plenum Press: NY and London, 1979; Vol 3, p 37.

14. Perrin, D. D. Stability Constants of Metal-Ion Complexes, Part B Organic Ligands; Pergamon Press: Oxford, UK, 1979; p 188.

15. Elchuk, S.; Burns, K. I.; Cassidy, R. M.; Lucy, C. A. J. Chromatography 1991, 558, 197-207.

16. Cornelius The Chemistry of the Transuranium Elements; Verlag Chemie GmbH: Germany, 1971; Vol 3, pp 217-229. 